\title{
APROXIMACION AL PROBLEMA DE LA INTEGRACION SOCIO. CULTURAL DE LOS INMIGRANTES EN CATALUÑA
}

\author{
Cariota Solé \\ (Universidad de Barcelona)
}

Rosa Junyent

(Escuela Superior de Sociologia

de la Diputación de Barcelona)

\author{
Faustino Miguélez \\ (Universitat Autònoma de Barcelona)
}

Antonio Izquierdo

(Universidad de Barcelona)

Este estudio analiza el problema de la integración en Cataluña de personas procedentes de otras tiertas de España, desde el punto de vista de la sociedad receptora, en su doble dimensión de sociedad industrialurbana, capitalista, dividida en clases; y cultural e históricamente delimitada. Se analiza la inmigración interregional hacia Cataluña distinguiéndola de los movimientos y desplazamientos de población intrarregionales o intracomarcales, vinculados a la movilidad ocupacional característica en una economía de mercado y que afecta tanto a la población activa autóctona como a la inmigrada hace años a Cataluña. Se parte asimismo del supuesto del abandono de la idea de retorno a la región de origen por parte de la gran mayoría de inmigrantes, tras un tiempo de permanencia en Cataluña, genetal. mente corto. 
Esta investigación no está terminada sino en plena realización. El interés de este artículo se reduce, por lo tanto, a la presentación de la serie de obstáculos que hemos encontrado en la primeta etapa de elaboración de nuestro trabajo, de los planteamientos de que hemos partido para intentar abordar estos obstáculos y de la tentativa de aproximarnos a un tema tan difícil y controvertido como importante para Cataluña.

En la primera etapa de nuestra investigación hemos intentado contraponer la visión más común y recurrente en la literatura sobre Cataluña como sociedad y ración con la opinión de varios inmigrantes sobre rasgos básicos definidores de la cultura catalana o características de instituciones como la Generalitat. El análisis del contraste entre la visión de Cataluña por parte de los inmigrantes y la población autóctona, que recientemente ha oficializado el Congrés de Cultura Catalana, contribuiría a la reflexión sobre problemas que afectan a todos y llevaría a replantear muchas cuestiones cruciales para el futuro de la sociedad catalana.

\section{Supuestos básicos}

La integración de los inmigrantes no catalanes en la sociedad industrial urbana presenta aspectos y problemas comunes, en lo que hace referencia a la «acomodación al trabajo industrial» con los que ha tenido el campesinado emigrado hacia los centros industriales de Barceiona y otras ciudades catalanas desde la Catalunya pobra. ${ }^{1}$ Pero, a diferencia de las migraciones en el interior de Cataluña, que pueden afectat similar y conjuntamente a la población de origen catalán o a inmigtados residentes en algún lugar

1. Las primeras páginas de esta comunicación forman parte del artículo que publicamos en la revista Materiales, 9 (1978). De ahora en adelante, al hablar de «inmigrante» nos referiremos a personas de origen no catalán, que vienen a instajatse en Cataluña. 
del Principado, desde hace varias generaciones, el hecho de instalarse en una sociedad culturalmente distinta de la de origen plantea problemas específicos para la masiva inmigración de los últimos años.

A nuestro entender, la integración de los inmigrantes es un proceso complejo que presenta varios aspectos interrelacionados que se suceden y tienen lugar sin seguir un orden ni un ritmo e intensidad preestablecidos - generalizables. Entre estos aspectos sobresalen la necesidad para el inmigrante de amoidarse al trabajo industrial y a las condiciones de la vida urbana, de adoptar normas y costumbres de la sociedad en que se instala y la toma de conciencia de ambos hechos que se tefleja en su inserción de clase --er el caso de la gran mayoría de los inmigrantes el proletariado industrial - y en la aceptación de la realidad nacional de Cataluña, habida cuenta de la interrelación sociocultural históticamente constante entre población autóctona e inmigrada.

Por último, tomamos el término y concepto de «integración», no como sinónimo de asimilación, que siempre se ha utilizado desde la perspectiva de acaparamiento de rasgos foráneos por parte de la clase dominante, pata adaptarlos a su imagen y semejanza, sino como la posibilidad de interacción en la totalidad de diversos elementos. ${ }^{2}$ Integración sociocultural se refere más a la consecución de una identidad colectiva a través de la conciencia e inserción de clase que al engrandecimiento de Cataluña como comunidad. El complejo proceso de la integración sociocultural involucra necesariamente a autóctonos e inmigrados en la meta común de transformar Cataluña en una sociedad emancipada en la cual los elementos socioculturales de las distintas poblaciones que la conforman queden libremente asumidos por todos sus miembros.

\section{Hipótesis de partida}

Dentro de las migraciones en sentido amplio producidas por la dinámica de una economía de mercado ( $y$, en general, por la progresiva industrialización de un país), la de mayor peso demográfico es la inmigración de carácter económico interregional hacia Cataluña, esto es, de trabajadores que buscan un puesto de trabajo o un empleo mejor remunerado y unas

2. Esta es la postura de autores como A. Badia i Margarit en La llengua dels barcelonins (Barcelona: Edicions 62, 1969), passim. También A. C. Comín y J. N. García Nieto los utilizan como términos sinónimos, sin detenerse en el contenido conceptual diferente en ambos, aunque sí los refieren a su dimensión de clase, en Juventud obrera y conciencia de clase (Madrid: Edicusa, 1974), p. 54. 
mejotes condiciones de vida (educación, sanidad, vivienda, etc.) para elios y sus hijos. Son estas causas y motivaciones las que hacen abandonar al campesino y al proletariado agrícola inmigrados a Cataluña la idea de retorno a la tierra de origen.

La sociedad catalana, como sociedad industrializada y urbana ofrece unas expectativas de instrucción, formación profesional y educación que, por el principio democtático formal de la «igualdad de oportunidades», permitirían a los inmigrantes - 0 con mayor probabilidad a sus hijosespecializarse progresivamente en actividades industriales $\dot{o}$ de servicios para ocupar, a largo plazo, lugares de trabajo más cualificados. Por otro lado, ello podiría abrirles las puettas a una actividad económica independiente (pequeño establecimiento comercial, taxi u otros servicios), considerada igualmente como indicador de promoción social, según el sistema de valores vigente en la nueva sociedad en la que se instalan.

A su Ilegada, los trabajadores inmigrantes tienden a ocupar los puestos de trabajo menos cualificados y peor remunerados, debido a su falta de formación socioprofesional. Por otra patre, en los centros industriales, la absorción de estos trabajadores resulta económicamente rentable para el capital, debido a los bajos salatios que perciben; y socialmente, por no ser aparentemente $y$ de forma inmediata fuente de conflictos laboral-sindicales y políticos para la empresa, dadas la vuinerabilidad jurídico-legal y supuesta aceptación por la mayoría de inmigrantes de las condiciones de trabajo a que les somete el patrono. Pero esta población inmigrante forma parte de la clase obrera de Cataluña, puesto que son unas mismas relaciones de producción las del conjunto del proletariado industrial.

Ahora bien, los obreros industriales de origen en el campesinado catalán, así como la población inmigrada y afincada desde varias generaciones en Cataluña, se encuentran ante una información más transparente de las condiciones de mercado, sobre todo en la industria y servicios, sectores cada vez mayores en extensión e intensidad productiva, que exigen de los trabajadores conocimientos técnicos y profesionales especializados. Asimismo, para esta población autóctona y afincada en Cataluña desde hace años existen posibilidades de educación y formación técnico-profesionales algo mayores que para los inmigrados, debido a su mayor tiempo de permanencia en el trabaio industrial.

Por otra parte, la movilidad ocupacional como indicador de integración es menor, en términos globales, para los inmigrantes que para los nativos. El desarrolio del sector servicios, de elevado nivel tecnológico, requiere personal cualificado. Los puestos de trabajo son cubiertos por población trabajadora autóctona, en proporciones casi idénticas a la población trabajadora inmigrada, en la década 1951-1959. A diferencia de esta 
década, el fujo inmigratorio de 1961 a 1974 estaba compuesto por trabajadores procedentes de Andalucía y Extremadura, en su mayor parte zonas con tasas elevadas de población no escolarizada y por tanto de un nivel de educación formal muy bajo. La afluencia de mano de obra no especializada y barata explica además la aparente y telativa movilidad ocupacional ascen. dente para la población autóctona o de inmigración anteriot. Sin embargo, la tasa de movilidad socioprofesional ha descendido enormennente desde 1966-1968. ${ }^{3}$

Teniendo en cuenta que los inmigrantes de reciente llegada a Cataluña (1960 a 1975, aproximadamente) ocupan en su gran mayotía trabajos manuales (un $80 \%$ de trabajadores manuales no cualificados son de origen no catalán), la situación actual de la población inmigrante en relación a su posición dentro de la estructura ocupacional ha empeorado, por cuanto se han acrecentado los empleos manuales y los rangos bajos de los no manuales, en consonancia con una relativamente tetardada mecanización y automación de la producción. ${ }^{4}$ La transparencia del mercado de trabajo y la posibilidad de reacción ante las condiciones que éste impone, es pues más evidente a la clase trabajadora en Cataluña, cuanto más conocedora y afectada históricamente por el sistema de economía de mercado en su fase actual. Este conocimiento condicionará el ritmo e intensidad de la integración socio. cultural de los obreros que han inmigrado, a grandes flujos, desde hace años hacia Cataluña.

Por otro lado, aunque la existencia de una lengua y cultura propias es vagamente conocida por el inmigrante, por la misma opresión política y social que ha sufrido el país, su contacto con la lengua y cultura catalanas ha sido sistemáticamente obstruido, a partir del mismo momento de acomodarse a la vida industrial y urbana en Cataluña. El contacto con la realidad catalana ha sido prácticamente inexistente en la vida diaria o a través de los medios de comunicación, además de la carencia de escuelas y escasa enseñanza en ellas del, y en, catalán.

La integración en una sociedad con unas características culturales pro. pias se ha visto diffcultada por obstáculos que no son los hipotéticos y potenciales prejuicios del inmigrado o su actitud defensiva ante el hecho catalán, sino por hechos objetivos y deficiencias estructurales de la sociedad catalana. Estos hechos objetivos son el gtan volumen de la inmigtación y la necesidad de los inmigtantes de concentrarse tanto en el lugar de

3. Esteban Pinilla de las Heras, «Una reconsideración: La inmigración», La Vanguardia (abril 1977).

4. Esteban Pinilla de las Heras, Immigració i mobilitat social a Catalunya (Barcelona: ICESB, 1973 y 1975). 
trabajo como en el de residencia. El aislamiento en los barrios, el escaso contacto con catalanes en los lugares públicos o contactos con la Administración que se realizan casi automáticamente en la lengua oficial (hasta ahora, sólo la castellana), han impedido también la concienciación de mưchos inmigrantes sobte la utilidad de aprender el catalán, al no sentirse acuciados directamente por la necesidad de emplearlo como lengua de relación o de comunicación. Las deficiencias estructurales son, por un lado, la falta de es* cuelas y la imposibilidad de educarse y formarse profesional y culturalmente; por otro, la impermeabilidad de los modernos medios de comunicación, controlados por el Estado -en especial en la época franquista-, a la lengua y cuitura catalanas.

Esta situación de precariedad estructural tiene corno efecto, el desarraigo de la propia cultura que afecta a la población autóctona con respecto a su lengua y cultura, y la no identificación con ellas de la población inmigrante. En el primer caso, es conocida la realidad diglósica que esconde el bilingüismo ambiental predominante en Cataluña, causada por la amplia opresión de la lengua y cultura catalanas durante siglos, y su feroz represión en las últimas décadas. ${ }^{5}$ En el segundo caso, la población inmigtante se encuentra ante un problema de desconocimiento y no identificación con la cultuta catalana que puede, a veces, expresarse en la teproducción parcial y/o esporádica de formas de vida de la comunidad de origen, en lugar de adoptar, de manera natural y sin imposiciones, pautas culturales de la sociedad receptora.

Por otra parte, sectores importantes del campesinado y pequeña bur* guesía urbana de Cataluña son de hecho monolingües catalanes, liegando a entender el castellano sin apenas hablarlo o escribirlo. A su vez, para los inmigtantes ya afincados o recientemente llegados a Cataluña, la realidad diglósica que tan profundamente afecta a los catalanoparlantes, ha podido servir indirectamente para paliar el contraste y conflicto entre dos lenguas en contacto, al tiempo que no ha motivado al inmigrante a conocer una segunda lengua. El inmigrante no siente la necesidad de aprender el catalán, ni tampoco el apremio de reafirmarse en su propia lengua, al ser el castellano la lengua dominante y oficial. ${ }^{6}$

Si la lengua del entorno fuera el catalán, coexistiendo con el caste. llano, se conseguiría neuttalizar la existencia de una lengua dominante -hasta ahora y por ahora, el castellano. El catalán acabaría por ser adop.

5. Francesc Vallverdú, Sociología y lengua en la literatura catalona (Madrid: Edicusa, 1971), pp. 49-63.

6. Esta afumación debetfa matizarse en el caso de inmigrantes gallegos, vascos $y$, en general, de personas cuys lengua matema no fuera el castellano. 
tado por los inmigrantes de forma natural. La lengua como vehículo esencial de transmisión de cultura, en su contenido y forma, se transformaría así en un medio seguro de integración sociocultural. En Cataluña, la exigencia de la restauración oficial, completa de la lengua entrafiaría la cooficialidad obligada y realmente asumida con aprendizaje del catalán en la escuela. ${ }^{\text {? }}$

Partiendo de la vinculación entre cultura y lengua, no puede afitmarse que exista correlación entre clase social y habla catalana o casteilana puesto que una clase social no se define por la lengua. En realidad, en Cataluña el catalán no es, ni ha sido únicamente, la lengua de la burguesía; es y ha sido también la lengua de las clases populares autóctonas, incluido gran parte del proletariado de hoy. Por otra parre, no puede afirmarse que el hecho de no haber aprendido el catalán signifique una menor integración a otros niveles, exceptuando el idiomático.

Aunque es muy probable que en la segunda y sucesivas generaciones, se ptoduzca un contacto más frecuente y directo de los inmigrantes con la lengua catalana, o por lo menos, que existan mayores posibilidades de que se produzca este contacto, la enseñanza del idioma es evidentemente necesaria en la tarea de integración en un país de inmigración masiva como es Cataluña $y$, en especial, si la población inmigrante ha abandonado en su mayoría, la idea de retorno a la región de origen. En el caso del inmigrante, la escuela le proporcionaría los instrumentos necesarios para acomodarse al trabajo industrial y condiciones de vida de la sociedad industrialurbana catalana, y se evitaría así, el peligro de una doble marginación. Peto debe tomarse en consideración la realidad de que muchos inmigrantes e hijos de inmigrantes puredan sentirse catalanes por haber nacido, vivir y/o trabajar en Cataluña, aun sin hablar el catalán y desconociendo, por supuesto, las raíces históricas y políticas que han creado esta situación.

\section{Planteamiento del problema}

Estas bipótesis han sido verificadas a través de 46 entrevistas, que han servido de pretest para la elaboración del cuestionario de la encuesta a realizar en el último trimestre de 1978. Las personas entrevistadas fueron contactadas por el equipo de investigación a través de asistentes sociales trabajando en los barrios, previamente seleccionados de: San Ildefonso (Cornellá), Bellvitge (Hospitalet), Torre Romeu (Sabadeli), y Las Roquetas (Barcelona). La elección de estas cuatro áreas, dependientes de centros

7. Ibidem, p. 110 . 
industriales-urbanos, internamente homogéneos se hizo por el tipo de habitante (trabajador inmigtante, procedente generaimente de ambiente rural, no catalán, subdesarrollado, y por el tipo de hábitat y entorno urbano (barrios de polígonos de reciente construcción, bloques de vivien. das de pequeñas dimensiones, barrios de viviendas autoconstruidas; aislamiento de los centros urbanos respectivos, etc.). Estas áreas son diferenciables entre ellas por la época de industrialización y afluencia de inmigrantes, temprana o tardía. Se eligieton estas zonas por tener mayor información bibliográfica y estadística que sobre el resto del cinturón industrial de Barcelona, y fácil acceso.

El guión para las entrevistas en profundidad contenía las siguientes preguntas:

\section{Datos básicos}

1. ¿De qué tegión es usted?

2. ¿Había emigtado a otra región de España antes de venir a Cataluña?

3. ¿En qué año llegó? Ciudad, pueblo, localidad o provincia.

4. ¿A qué edad llegó? ¿Cuántos años tenía usted?

5. ¿Había ido al colegio en el lugar de origen? Estudios o cualificación profesional.

6. ¿Qué trabajo realizaba en el lugar de origen?

7. ¿En qué condiciones de trabajo y salario, relaciones con el patrono realizaba allí? Asalariado (fijo o eventual) o no.

8. ¿Cuáles han sido los diversos trabajos que ha hecho en Cataluña? (Historia de los trabajos y situación laboral.)

9. ¿Qué trabajo realiza en la actualidad? Categoria, asalatiado (fijo o eventual) o no.

10. ¿En qué barrios diferentes ha vivido desde que llegó a Cataluña?

11. ¿En qué viviendas vivió desde que llegó a Cataluña? ¿Qué forma tuvo de encontrarlas; qué organismos se las proporcionó?

12. ¿A qué escuela van sus hijos? Del mismo bartio o no; privada o estatal.

13. ¿Está en algún partido, sindicato o/y asociación de vecinos?

14. ¿Desde cuando está en su partido, sindicato y/o asociación de vecinos? 
Situación ocupacional-laboral

1. ¿Qué diferencias encontró entre trabajar en el campo, en su pueblo, y trabajar en la industria, en la ciudad?

2. ¿Qué posibilidades ha tenido y tienen de aprender mejor su oficio desde que llegó a Cataluña?

3. Los trabajos que ha realizado, ¿son los que pensaba que haría al emigrar? ¿Qué problemas ha encontrado para cambiar de trabajo?

4. ¿Qué diferencias ha encontrado entre cobrar un salario en la industria y cobtat un jornal en el campo? ¿Qué diferencias en el trato y la relación hay con un patrono en el campo y con el patrono en una empresa industrial?

5. ¿Cree que los catalanes tienen más facilidades para encontrar trabajo y cambiar de faena que los inmigrantes? ¿Por qué?

6. ¿Qué luchas importantes ba vivido en su empresa?

7. ¿Ha visto diferencias de actitud entre catalanes e inmigrantes en las luchas obretas en su empresa?

8. ¿Ha notado en su empresa, diferencias entre líderes obreros inmigrantes y catalanes; en saber organizar la lucha, en discutir las teivindicaciones, en llevarse a la gente?

\section{Vivienda y vida en el barrio}

1. ¿Cree que su batrio está bien comunicado?

2. ¿Va al centro de Barcelona a menudo?

3. ¿Qué encuentra a faltar en su barrio?

4. ¿Cree usted que existen barrios donde mayormente viven inmigrantes y barrios donde viven catalanes de origen? ¿Por qué?

5. ¿Tienen contacto con catalanes (amistad, vecindaje)?

6. ¿Ha tenido dificultad en hacer amigos catalanes?

7. ¿Participa en la Asociación de Vecinos de su bartio? ¿Va a las Asambleas o es miembro de alguna de las Vocalías?

8. ¿Cuántos inmigrados y cuántos catalanes hay en la Junta de su Asociación de Vecinos?

9. AAsiste a actos culturales organizados en centros catalanes de su batrio? Si es que no existen, ¿a qué centros van los intrigrantes?

10. ¿Van los catalanes a actos que se organizan en los centros de inmigrantes?

11. ¿Qué acción y cuáles han sido las reivindicaciones más importantes en su barrio, que han movilizado a más gente?

12. ¿Participan en ellas, inmigrantes y catalanes, por igual? 
Integración socio-cultural de los inmigrantes en Cataluña

\section{Lengua y cultura catalanas}

1. ¿Entiende usted el catalán? ¿Lo habla? Si contesta que no: ¿por qué?

2. ¿Cree necesario hablar, o por lo menos, entendet el catalán? ¿Por qué?

3. ¿Piensa que todos los niños, inmigrantes y catalanes, deberían aprender el catalán en la escuela? ¿Deberían ser los estudios en catalán?

4. ¿Le parece que en el Ayuntamiento y Juzgados debería hablarse en catalán? ¿Por qué?

5. ¿le parece que las películas de cine o la TV deberían ser en catalán?

6. Si contesta que no: ¿deberían ser habladas en catalán y castellano?

7. ¿Qué entiende usted por «cultura catalana»?

8. ¿Qué diferencias hay entre la cultura catalana y la cultura de su región de origen? ¿le parece «superior» la catalana?

9. ¿Sigue al Barça? ¿Es usted socio?

10. ¿Conoce a cantantes catalanes? ¿Cuáles le gustan más? ¿Ha estado en algún recital de la Cançó Catalana? ¿Los ha oído por TV?

11. ¿Se ha casado algún miembro de su familia con catalanes?

\section{Participación politica y sindical}

1. ¿En qué momento y a qué edad se dio cuenta y empezó a participar en la acción política y sindical? ¿Por qué?

2. ¿Cree que en la campaña electoral se trató el problema de la inmigracion? ¿Qué aspectos fueron los tratados con más hontadez y seriedad?

3. ¿Hubiera votado a un partido político sin vínculos con otros partidos hermanos del resto de España? ¿Por qué?

4. ¿Conoce usted a Juan de Dios Ramírez Heredia, y a J. Acosta Sánchez? ¿Qué piensa de su intento de atraerse los votos de inmigrantes?

5. ¿A quién votó para el Senado?

6. ¿Conocía a Benet, Candel, Xirinachs, antes de las elecciones del 15 de junio de 1977? Si les votó; ¿por qué lo hizo?

7. ¿Estuvo en la Diada? ¿Por qué?

8. ¿Cree que fueton muchos inmigrantes a la Diada?

9. ¿Estuvo en el Día de Andalucía? ¿Por qué? 
10. ¿Cree que fueron muchos inmigrantes al Día de Andalucía?

11. ¿Qué cree usted que significa la autonomía para Cataluña y para Andalucía?

12. ¿Piensa usted que la autonomía para Cataluña beneficiará más a los catalanes que a los inmigrantes que viven aquí?

13. ¿Fue a recibir a Tarradellas?

14. ¿Qué piensa de Tarradellas y de la actual Generalitat?

15. ¿Qué piensa sobre la opinión de que Cataluña es la que explota a Andalucía, y de que son los catalanes los que explotan a los inmigrantes?

\section{Otras preguntas}

1. ¿Qué ventajas encuentra en vivir en Cataluña?

2. ¿Si pudiera, volvería a su región de origen? ¿Por qué?

3. ¿Cree que he olvidado de preguntarle por algún problema importante para los inmigrantes?

4. ¿Qué añadiría a esta entrevista?

\section{La mujer inmigrante}

1. ¿Viniste sola, con tus padres, o tu matido, a Cataluña?

2. ¿Quién cuida de los niños cuando tú trabajas?

3. Si trabajó de sirvienta, ¿hubiera preferido ir a la fábrica? ¿Por qué? Si no trabaja: ¿Qué vida lleva en el barrio? (Si se aburre.)

4. ¿Piensas que en Cataluña hay más libertad para las mujeres? ¿En qué sentido y aspectos?

5. ¿Piensas que en la familia las hijas de inmigrantes tienen una vez instalados en Cataluña unas relaciones con sus padres más liberales, libres?

6. ¿Crees que las mujeres catalanas tienen más libertad con respecto a sus maridos, que éstos no someten tanto en lo que hacen (si salen, si ven a amigas, si se compran algo sin decirlo a sus maridos) que los varones en Andalucía?

7. ¿Crees que hay que tenet los hijos que vengan o es mejor controlar cuántos hijos se quieren? ¿Conoces anticonceptivos? ¿Qué piensas del aborto?

8. ¿Qué piensas del divorcio? ¿Crees que vale más divorciarse a que los hijos vean pelearse a sus padres? 
9. ¿Has tenido presión familiar para ir a trabajat fuera de casa en Cataluña? ¿Y en Andalucía?

10. ¿Has sentido discriminación por ser mujer e inmigrante en tu empresa?

11. ¿Qué acciones han movilizado a más mujeres dentro de tu empresa?

12. En el barrio, ¿qué teivindicaciones han movilizado a más mujetes?

13. QQué problemas en la Asociación de Vecinos interesan más a las mujeres? ¿En tu Asociación de Vecinos qué vocalías llevan las mujeres?

14. ¿En tu barrio, asisten muchas mujeres a actos culturales o politicos, si se hacen a horas convenientes? (Cuando los niños están en el colegio.)

15. ¿En tu partido, qué tipo de actividades desempeñan las mujeres? ¿Estás de acuerdo con ellas?

Para «medir» el subproceso de «acomodación al trabajo industrial» los indicadores más clatos son: 1. La diferencia entre trabajo en el campo y en la industria, en el pueblo o en la ciudad. 2. Mayores posibilidades de encontrar trabajo, de movilidad ocupacional, de promoción en Cataluña para los no conocedores de la lengua; presentan las frecuencias más elevadas en la tabla de valoración de las entrevistas en profundidad ${ }^{8}$ Otros indicadores como: mayor facilidad de los catalanes por conocer el mercado de trabajo, porque tienen mayor cualificación tienen una frecuencia menor. En cuanto a la actitud "pasiva» o "no activa» de los catalanes y no catalanes en los conflictos de empresa, las frecuencias son elevadas entre las respuestas de: no hay diferencia, actitud más lanzada de los inmigtantes. La frecuencia para la respuesta de actitud más razonada y cabal de los catalanes es mucho menot. Los líderes de empresa son vistos por los inmigrantes como más «lanzados» y mejores cuando no son nacidos en $\mathrm{Ca}_{a}$ taluña.

Las variables que miden el subproceso de «adaptación a la vida urbana» que se concretiza en vida en los barrios presentan sus frecuencias más elevadas en la falta de equipamientos, infraestructura, etc., seguida por la dificultad de comunicación entre la gente en los barrios obreros. El contacto con catalanes a la hora de hacer amistad no parece ser excesiva-

8. Estas «frecuencias》 deben considerarse entre comillas. No pueden sacarse porcentajes fidedignos de los datos recogidos de las 46 entrevistas en profundidad, una vez vaciadas por el método de análisis de contenido de respuestas cualitativamente muy diversas. Esta consideración afecta especialmente al «no contesta», «no sabe» y «no quiere contestar». 
mente dificultoso a pesar del caxácter cerrado, reservado de los catalanes en opinión de los inmigrantes entrevistados. Otra variable intentaba medir la participación y vida asociativa de los inmigrantes en sus bartios. A pesar de la falta casi total de centros de todo tipo en estos barrios, la partici* pación en los actos que se celebran en ellos es proporcional a la población catalana e inmigrante de estos núcleos.

Es muy elevada la frecuencia de conocimiento del catalán al nivel de entenderlo, pero no de bablatlo, de los inmigrantes. Las tazones que se aducen para explicar este indicador que nos «mide» la interrelación sociocultural de los inmigrantes en Cataluña son de diverso tipo, desde «es necesario conocer el catalán porque es un grado más de cultura» hasta «es necesario porque vivimos en Cataluña, convivimos con los catalanes». La cooficialidad del catalán junto con el casteliano en la vida pública y en los medios de comunicación de masas es aceptada por una gran proporción de inmigrantes. La condición sine qua non es, sin embargo, que el catalán a los niños se enseñe en la escuela y a los adultos en centros culturales. Ahora bien, la percepción de los inmigrantes de la cultura catalana no es en absoluto la de que sea superior a la propia cultura de la región de ori. gen. Es fruto de una forma de producir que se refleja en una forma de vida, de expresión, de costumbres propias de un pueblo. En algunos casos se confunde con educación. Como anécdota, el cantante catalán más conocido entre los inmigrantes que hemos entrevistado figura Joan Manuel Serrat seguido de Lluís Llach y Raimon.

El cuarto indicador de integración lo definiamos como el de participación política y sindical, teflejo de la inserción de los trabajadores inmigrantes en una de las clases fundamentales de Cataluña. La participación política y sindical puede medirse a través de la afiliación a partidos políticos, sindicato y asociación de vecinos. En las áreas o zonas que elegimos para realizar las entrevistas, los partidos obretos comunista y socialista tenían las frecuencias más elevadas, seguidos por CDC. La Entesa, y de ella Benet, exan conocidos antes de las elecciones del 15 de junio por una proporción relativamente elevada de gente en estos barrios. La asistencia a la Diada del 11 de septiembre de 1977 presenta frecuencias muy elevadas. Las razones que se dan para esta asistencia van desde: asistir por disciplina de partido a «fui porque me siento catalán y lucho por las instituciones de Cataluña». La asistencia al Día de Andalucía del 4 de diciembre de 1977 fue menor, según algunos, por estar peor organizada y ser menos unitaria. La autonomía y la Generalitat son comprendidos mayoritariamente (frecuencias muy elevadas) como «autoadministración, autogobierno», entendiendo que de ser democrático beneficiaría por igual a catalanes e inmigrantes. Tarradellas es muy impopular entre los inmigrantes que entrevistamos. La gran mayoría 
no fue a recibirle, unos pocos fueton por curiosidad. La opinión sobre Tarradellas y la actual Generalitat que recibe frecuencias más elevadas es la de que "Tarradeilas no hace nada por Cataluña», «es un hombre de derechas», seguida por la opinión de que «hay que espezar un poco a que pueda demostrar lo que puede hacer» (fecha de las entrevistas: de febrero a abril de 1978).

Finalmente, ante la pregunta del cuestionario sobre si es Cataluña quien explota a los inmigrantes, la opinión más frecuente es la negativa. Sobre la posibilidad de volver a la tierra de origen las respuestas de mayor frecuencia fueron contrarias al retorno, por las mayores oportunidades para los hijos, más medios (trabajo y vivienda) en Cataluña, a pesar de la morriña. De la serie de preguntas sobre la mujer inmigrante no pueden sacarse conclusiones dignas de mención por ser sólo siete las mujeres que contestaron a nuestras preguntas.

\section{Conclusiones provisionales}

Estas consideraciones ponen sobre el tapete la complejidad del tema de la integración sociocultural de una población que se ha visto obligada a emigrar de su lugar de origen para encontrar trabajo y sustento, y que es castellano-parlante en su gran mayotía, en una nación oprimida en su lengua y su cultura.

Una primera cuestión que debe conjugarse es el derecho de toda persona a hablar en su propia lengua con el derecho a la absoluta movilidad física de todo español en el territorio de España, con el derecho a la igualdad de oportunidades de trabajo y vida para todos los ciudadanos. La inserción de clase contribuye, en principio, a que los inmigrantes participen activamente en la vida política de Cataluña. Pero esta etapa o nivel en el proceso de integración sociocultural se dará a la larga necesariamente en todos los casos de migraciones de países o zonas pobres a países o zonas ricas. La emigración de españoles a Alemania, por ejemplo, corresponde a este tipo de problema. Ahora bien, no por ser inmigrantes en Alemania, los españoles en Frankfurt o Düsseldorf quieren «hacerse» alemanes, integratse en la cultura alemana, por muchas ventajas que esto comportata para ellos y sus bijos. Emigrar a Cataluna para un andaluz no es presumiblemente lo mismo que emigrar al extranjero. Le asisten sus derechos como ciudadano español y su conocimiento de una lengua entendida por todos los catalanes y hablada por su grandísima mayoría, aparte de que sus intereses sociales y políticos puedan estar representados por organizaciones homólogas a las de su región o de otras partes de España. 
«Papers»: Revista de Sociología

Esta situación, ventajosa con respecto al hecho de emigrar al extranjero, entraña a su vez la solución de difíciles problemas. En primer lugar, el hecho de que las libertades nacionales fueran suprimidas y la lengua fuera oprimida en Cataluña, no justifica que ahora los catalanes quieran imponer el catalán como única lengua. Por otro lado, como reacción a la opresión de la lengua, los catalanes han tomado a ésta como baluarte de sus reivindicaciones nacionalistas. Bajo el tégimen de Franco la identificación de "nacionalismo» con «izquierda» no permitía matices. El nacionalismo era perseguido bajo la dictadura, sin distinción de las diferencias ideológicas y de clase entre los diferentes movimientos nacionalistas en España. En la actualidad, esta identificación no puede mantenerse de la forma mecánica como se ha hecho en épocas de opresión continuada y dura. Esta y otras cuestiones deberían replantearse a la luz de la evolución democrática de nuestro país.

Carlota Solé

Departamento de Sociología

Facultad de Ciencias Económicas

Universidad de Barcelona

Pedralbes

Barcelona 